\title{
Descrição anatômica do esqueleto de avestruz (Struthio camelus): relato de caso
}

\author{
Ana Greice Borba Leite * \\ Lívia Maria Gomes Simões Silvério \\ Gésika Maria da Silva \\ Ana Gabriela dos Santos Araújo \\ Daniela Oliveira \\ Laboratório de Anatomia Animal, Unidade Acadêmica de Garanhuns \\ Universidade Federal Rural de Pernambuco \\ Avenida Bom Pastor s/n, Boa Vista, CEP 55.292-901, Garanhuns - PE, Brasil \\ * Autor para correspondência \\ ag_mv530@hotmail.com
}

Submetido em 20/02/2012

Aceito para publicação em 06/07/2012

\section{Resumo}

O avestruz (Struthio camelus) é uma ave que se caracteriza por seu grande porte, podendo atingir $2,8 \mathrm{~m}$ de altura e pesar acima de $150 \mathrm{~kg}$. Tem origem egípcia e depois se difundiu por toda a África. A criação comercial teve início há cerca de 150 anos, com a domesticação de animais nativos da África do Sul, país que ocupa a liderança no fornecimento de carne. Várias doenças musculoesqueléticas foram observadas em aves de rápido crescimento, como o avestruz. O elevado peso corporal, associado a uma estrutura óssea em formação, é citado como a principal causa de disfunções do aparelho locomotor. Neste trabalho, utilizou-se um espécime macho adulto, proveniente de uma fazenda de produção de avestruzes, localizada no município de Paranatama, PE. Após a retirada dos tecidos moles, as mensurações dos ossos foram realizadas com paquímetro e fita métrica, e cada osso foi fotodocumentado e descrito. Este estudo almeja contribuir para aumentar o conhecimento sobre o sistema ósseo do avestruz, além de ser base para o desenvolvimento muscular, um dos principais alvos da exploração comercial em relação a essa espécie.

Palavras-chave: Morfologia; Osso; Ratitas

\section{Abstract}

Anatomical description of the ostrich (Struthio camelus) skeleton: case report. Ostrich (Struthio camelus) is a bird characterized by its large size, it can achieve $2.8 \mathrm{~m}$ in height and weight over $150 \mathrm{~kg}$. It has an Egyptian origin and then spread throughout Africa. Commercial breeding began about 150 years ago, with the domestication of native animals from South Africa, country which holds the first position in meat supply. Several musculoskeletal diseases were observed in fast-growing birds, such as ostrich. High body weight, associated to a developing bone structure, is indicated as the main cause of disorders of the locomotor system. In this study, an adult male specimen was used, from an ostrich production farm located at the town of Paranatama, Pernambuco, Brazil. After removing soft tissues, bone measurements were performed with caliper and tape 
measure, and each bone was photographed for documentation and described. This study aims to contribute to increase knowledge on the ostrich skeletal system, as well as provide a basis for muscle development, one of the main targets of commercial exploitation with regard to this species.

Key words: Bone; Morphology; Ratites

\section{Introdução}

O avestruz (Struthio camelus) é uma ave que se caracteriza por seu grande porte podendo atingir $2,8 \mathrm{~m}$ de altura e pesar acima de $150 \mathrm{~kg}$. Tem origem egípcia e depois se difundiu por toda a África. São aves ratitas, longevas, atingindo até 70 anos e apresentam excelência reprodutiva, em média, por 40 anos, porém nunca perdendo a fertilidade (CEPLAC, 2008).

A criação comercial teve início há cerca de 150 anos, com a domesticação de animais nativos da África do Sul, país que ocupa a liderança no fornecimento de carne. Do animal abatido, aproveitam-se quase tudo, principalmente, carne, couro, plumas e ovos, destes inclusive a casca. Embora se trate de uma ave, o animal não apresenta músculos peitorais desenvolvidos como o pato ou o frango. A maior quantidade de carne está localizada nas coxas e no dorso (NOGUEIRA JÚNIOR, 2005).

Segundo Oliveira (2005), várias doenças musculoesqueléticas foram observadas em aves de rápido crescimento, sendo o elevado peso corporal, associado a uma estrutura óssea em formação, citados como as principais causas responsáveis pela ocorrência de doenças, resultando em disfunções do aparelho locomotor. Portanto, este trabalho pretende contribuir com os estudos do sistema ósseo do avestruz, que além de ser base para o desenvolvimento muscular é um dos principais alvos da exploração comercial da espécie.

\section{Material e Métodos}

Utilizou-se um espécime de avestruz adulto, macho, proveniente de uma fazenda de produção de avestruzes, localizada no município de Paranatama, PE, imediatamente após o abate. Todos os tecidos moles foram retirados e os ossos foram imersos em solução de peróxido de hidrogênio a $10 \%$ por trinta minutos. Após esse tempo, os ossos foram passados em água corrente, os tecidos moles remanescentes foram retirados e as peças foram secas ao sol. As mensurações foram realizadas com paquímetro e fita métrica. Cada osso foi fotodocumentado e descrito. As denominações das estruturas descritas seguiram as recomendações da Nomina Anatomica Avium (BAUMEL, 1993).

\section{Resultados e Discussão}

\section{Esqueleto Axial}

O avestruz utilizado no estudo possui um crânio pequeno e delicado com ossos leves e delgados (Figura 1A). O comprimento foi de $23 \mathrm{~cm}$ desde a extremidade rostral do osso nasal até a extremidade caudal do occipital. Segundo Dyce et al. (2004), vários ossos do crânio consistem de duas lâminas separadas por osso esponjoso, portanto, são mais espessos do que se poderia supor e dão a impressão de que a cavidade craniana é maior do que realmente aparenta. De acordo com Cubas et al. (2006), a cabeça da avestruz é relativamente pequena e chata, ao contrário dos pica-paus que sofreram adaptações anatômicas como o espessamento dos ossos do crânio, para proteger o cérebro de concussões durante fortes bicadas em madeiras e os psitacídeos que possuem a cabeça proporcionalmente grande e larga e o pescoço curto.

A mandíbula do avestruz (Figura 1B) apresentou $18,5 \mathrm{~cm}$ de comprimento, $7 \mathrm{~cm}$ de largura na região sublingual e $7,5 \mathrm{~cm}$ na distância entre os corpos direito e esquerdo, medidas que relacionam a largura e abertura do ângulo. Segundo Dyce et al. (2004), nas aves a mandíbula consiste de dois ossos delgados que se fundem rostralmente, onde são cobertos pelo bico inferior. 
FIGURA 1: Imagens fotográficas dos ossos do esqueleto axial de avestruz macho, adulto. A) órbita (1), processos mediais das maxilas (seta preta) e osso nasal (seta branca). B) a mandíbula consiste de dois ossos delgados. C) vértebras cervicais, com ganchos laterais (setas). D) costela vertebral, notar o processo uncinado (seta). E) esterno em vista ventral, tuberosidade lateral (seta fina) e processo esternocostal (seta grossa). F) acetábulo (1), orifício obturado (2) e o púbis (seta).

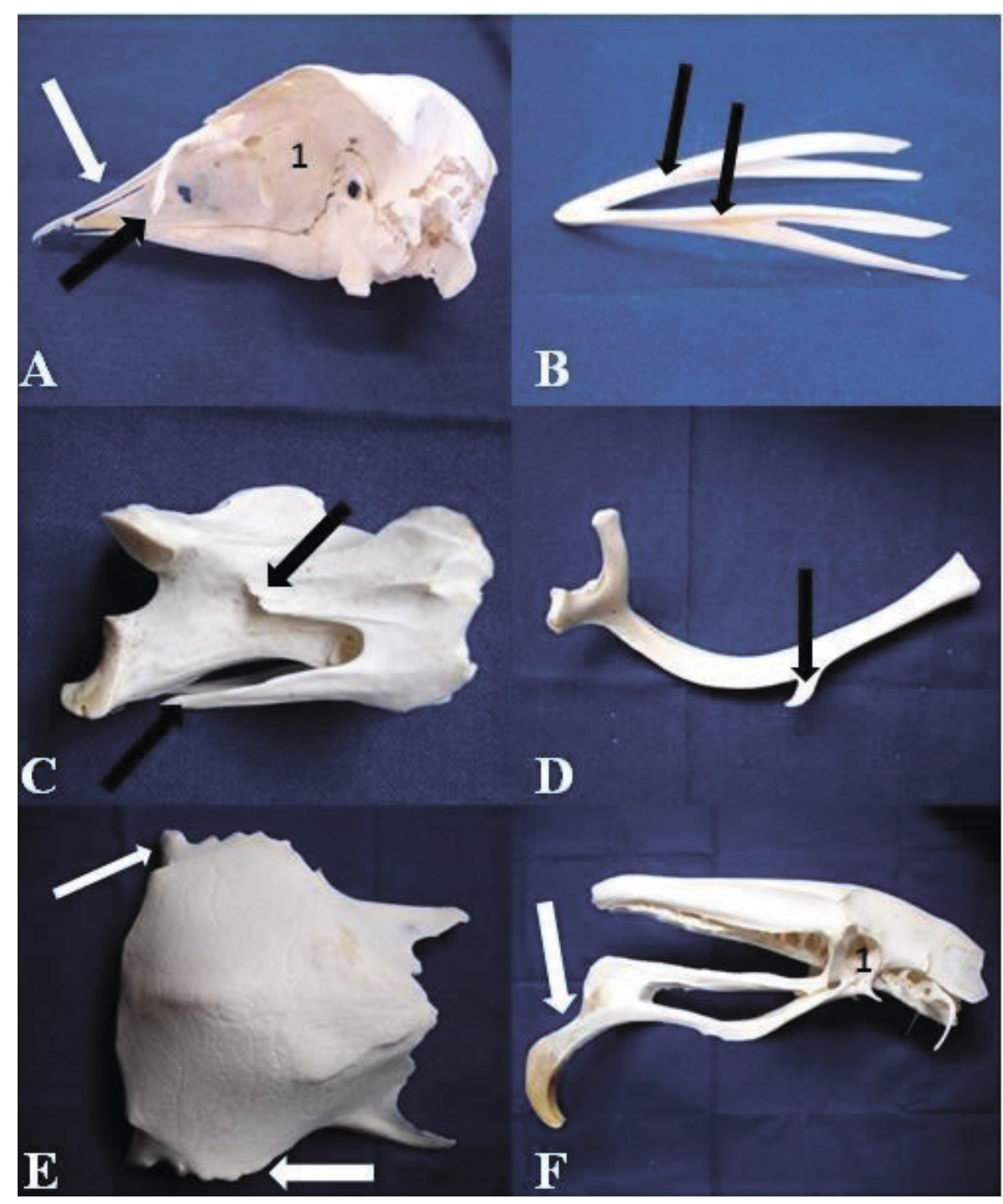

Nesse estudo verificou-se que o vômer possuía uma sínfise ventral de $2 \mathrm{~cm}$ de comprimento, que conecta a parte direita à parte esquerda do palato. $\mathrm{O}$ processo maxilar do palatino possuía $10,5 \mathrm{~cm}$ de comprimento e o palatino $2 \mathrm{~cm}$ de extensão. $O$ rostroparatireóide tinha $4,3 \mathrm{~cm}$ de extensão, o pterigóide possuía $2 \mathrm{~cm}$, o quadrado possuía $3 \mathrm{~cm}$ de largura e $2,5 \mathrm{~cm}$ de comprimento. $\mathrm{O}$ maxilar estava inteiramente ligado com septo nasal e seu ápice apresentou-se bem mais saliente em relação ao segmento caudal. $\mathrm{O}$ maxilar apresentava $11 \mathrm{~cm}$ de comprimento medial, liga-se com o septo interorbital possuindo, também, $11 \mathrm{~cm}$ lateral, entre as órbitas. Nas aves o osso nasal é dorsal e, em muitas, os psitacídeos, por exemplo, forma uma conexão cartilaginosa flexível com o osso frontal, permitindo que o maxilar seja levantado à medida que a mandíbula é abaixada (DYCE et al., 2004). De acordo com Getty (1986), o osso nasal é um osso complexo em todas as aves e as maxilas nas aves são grandemente reduzidas quando comparadas com outros grupos de vertebrados e são pequenos ossos delgados que se estendem medialmente como processos mediais das maxilas. Nos avestruzes as órbitas são 
bem desenvolvidas, no avestruz estudado as mesmas possuíam $3,5 \mathrm{~cm}$ de diâmetro e uma profundidade lateromedial ventral de $4 \mathrm{~cm}$, e um septo interorbital com $2,5 \mathrm{~cm}$ de largura e $4,5 \mathrm{~cm}$ de comprimento. O osso temporal possuiu $6 \mathrm{~cm}$ de comprimento e o lacrimal $2,4 \mathrm{~cm}$ de comprimento.

$\mathrm{O}$ avestruz estudado apresentou 26 vértebras, sendo que 15 delas cervicais, 11 torácicas e dez vértebras caudais. De acordo com Dyce et al. (2004), o número de vértebras cervicais nas aves varia com o comprimento do pescoço. Aves pequenas podem ter apenas oito, enquanto os cisnes têm até 25 , na galinha esse número varia de 14 a 17. Com relação ao avestruz, as duas últimas vértebras torácicas são intimamente ligadas com as vértebras do sinsacro e a última vértebra caudal é chamada de pigóstilo, que se apresenta como um osso plano em forma de quadrado. O pigóstilo consiste de vários rudimentos fundidos e dá sustentação às penas de vôo da cauda (DYCE et al., 2004). Semelhante ao avestruz quanto à forma, o cisne apresenta a coluna em formato de " $\mathrm{S}$ ", porém com 23 vértebras cervicais (ARTONI et al., 2001).

$\mathrm{O}$ atlas do avestruz, a primeira vértebra cervical, que se articula com o único côndilo do crânio, apresentou $2,3 \mathrm{~cm}$ de largura, $0,4 \mathrm{~cm}$ de comprimento dorsal, $0,6 \mathrm{~cm}$ de altura e $1,2 \mathrm{~cm}$ de comprimento ventral. $\mathrm{O}$ áxis é mais desenvolvido, com $2,8 \mathrm{~cm}$ de largura, $2,1 \mathrm{~cm}$ de comprimento e as demais vértebras cervicais tiveram um aumento de tamanho ao longo da coluna. A partir da terceira vértebra cervical surge um desenvolvimento da região dorso-lateral que lembra ganchos (Figura 1C), que ajuda na articulação do pescoço nos sentidos dorsal e ventral sem que saiam do eixo em movimento de 180 graus. Da $15^{\mathrm{a}}$ à $24^{\mathrm{a}}$ vértebra, existiu um crescimento gradativo do processo espinhoso. A partir da segunda vértebra caudal ocorria a formação do processo transverso, sendo esse mais destacado nas $15^{\mathrm{a}}, 16^{\mathrm{a}} \mathrm{e}$ $17^{\mathrm{a}}$ vértebras. A décima vértebra caudal (pigóstilo), que tem origem a partir da fusão de três vértebras caudais, não possuiu processo transverso, mas há um processo espinhoso bem desenvolvido. De acordo com Oliveira (2006), o número de vértebras em cada segmento vertebral é constante para cada espécie aviária, mas pode variar entre as espécies e diferenciar o limite exato entre as vértebras cervicais e torácicas, ou entre lombares e sacrais.

O avestruz possuiu nove pares de costelas (Figura 1D), sendo que cada costela se articulava com apenas uma vértebra. As costelas verdadeiras, as que se articulam com o esterno, são formadas por dois ossos que são unidos por uma cartilagem. As cabeças das costelas vertebrais se articulam com o processo transverso das vértebras e os tubérculos, com o corpo da vértebra. Nas costelas vertebrais, os três primeiros pares apresentaram processo uncinado, uma protuberância na borda caudal, que se dirige caudodorsalmente e se sobrepõe parcialmente sobre a costela seguinte. As costelas esternais são ossos finos e planos que se alargam na extremidade ventral, onde se articulam com o esterno no processo esterno costal.

O esterno do avestruz (Figura 1E) consistia em um osso levemente côncavo voltado para a face dorsal, com forames localizados dorsalmente e com ausência da quilha. Apresentou $29 \mathrm{~cm}$ de comprimento e $25 \mathrm{~cm}$ de largura na região mais côncava. Na borda cranial do esterno encontraram-se duas tuberosidades laterais, uma em cada lado. Ainda na face ventral, cranialmente, ocorreu a formação de dois sulcos, um do lado do outro, formando uma borda evidente. $\mathrm{Na}$ sua borda caudal, encontraram-se dois processos de parede bem delgada, sendo unidos por uma borda bem irregular, onde se encontra a cartilagem do esterno. No esterno, nas bordas laterais, foram encontrados os processos esternocostais bem proeminentes, local onde ocorreu a articulação das costelas esternais. Segundo Getty (1986), há grande variação na borda caudal do esterno nas aves, algumas possuem apenas duas incisuras, por exemplo, patos, e algumas possuem bordas caudais sólidas com apenas fenestras, por exemplo, muitos papagaios, ou são totalmente sólidos, por exemplo, avestruzes. Com relação às galinhas, elas possuem um esterno relativamente longo e estreito, e, embora sejam más voadoras, elas possuem uma quilha bastante profunda (DYCE et al., 2004).

A pelve (Figura 1F) apresentou-se bem alongada craniocaudalmente formada por três ossos (ilíaco, ísquio e púbis), possuiu $61 \mathrm{~cm}$ de comprimento na face dorsal. $\mathrm{O}$ orifício obturado era bem evidente, a tuberosidade 
coxal, suave e a tuberosidade isquiática apresentouse arredondada. O púbis era curvado cranialmente e apresentou a sínfise pélvica. No cisne a parte final e caudal é alargada e curvada caudocranialmente, enquanto que no galo e no pombo esta parte final é estreita e curvada caudomedialmente (ARTONI et al., 2001). Também na pelve do avestruz, encontrou-se o acetábulo, cavidade na qual irá se articular a cabeça do fêmur, que é formada pela união do ilíaco, ísquio e púbis. No cisne, o púbis está ausente e o acetábulo assemelha-se a um anel ósseo, ligeiramente ovalado, que se articula com a cabeça do fêmur (ARTONI et al., 2001).

\section{Esqueleto apendicular torácico}

O membro torácico do avestruz estava constituído por quatro ossos, além da mão e seus dígitos. A escápula (Figura 2A) era o mais proximal dos ossos e apresentouse fundida ao coracóide. As escápulas encontraram-se separadas pela $17^{\circ}$ vértebra cervical, na qual se articulam em uma face articular. A escápula possuiu $30,5 \mathrm{~cm}$ de comprimento, nos $15 \mathrm{~cm}$ de comprimento proximal se apresentou como um osso plano, tendo $7,5 \mathrm{~cm}$ de largura uniforme. Na região proximal da escápula é encontrado um forame de diâmetro $5 \mathrm{~cm}$, de proximal a distal. Ainda nessa região encontraram-se duas tuberosidades laterais relativamente evidentes, e nesse mesmo comprimento, a cavidade glenóide, na face caudal da escápula, articulouse com a cabeça do úmero. No cisne, ela é ligeiramente mais espessa em sua extremidade proximal, e próximo ao acrômio há um forame de acesso ao seio deste osso (ARTONI et al., 2001).
O úmero (Figura 2B) é o segundo osso que constitui o membro torácico do avestruz e o maior deles, apresentando $38,5 \mathrm{~cm}$ de comprimento e $6,5 \mathrm{~cm}$ de circunferência na região da diáfise. Possui uma cabeça pequena, que se articula com a cavidade glenóide. O tubérculo maior era bem destacado, enquanto o menor se limitou a uma pequena protuberância. Não possuiu o sulco intertubercular, e a tuberosidade deltóide apresentou-se como uma pequena rugosidade na superfície do osso. A tuberosidade para o redondo maior encontrou-se medial e distal à epífise proximal no avestruz. Na sequência, notou-se uma borda na face medial da diáfise. A diáfise não apresentou o sulco para o músculo braquial e nem a epífise distal apresentou a fossa radial, como nos mamíferos (DYCE et al., 2004). A fossa do olécrano apresentou-se como um sulco que divide muito superficialmente a epífise distal. A face cranial da epífise distal não apresentou uma divisão evidente, no entanto, é distinguível a tróclea e o capítulo que se apresentaram sem grandes diferenças como nos mamíferos, sendo o capítulo ligeiramente maior que a tróclea. Ainda na epífise distal encontraram-se os epicôndilos, sendo o epicôndilo lateral mais destacado que o epicôndilo medial. Segundo Dyce et al. (2004), os ossos longos das aves possuem córtices finos, frágeis, impróprios à colocação de placas ou pinos, que poderiam ser considerados para o reparo de fraturas em grandes aves de gaiolas.

Na sequência encontraram-se o radioulna (Figura 2C), cujo espaço interósseo era bem evidente, de $2 \mathrm{~cm}$ entre as diáfises dos dois ossos.

FIGURA 2: Imagens fotográficas do esqueleto apendicular torácico de avestruz macho, adulto. A) escápula apresentando a cavidade glenóide (seta maior), forame na região proximal (1), borda cranial (seta menor). B) úmero. C) rádio (seta maior) e ulna (seta menor), tuberosidade lateral na epífise proximal da ulna (2), espaço interósseo bem evidente (*).

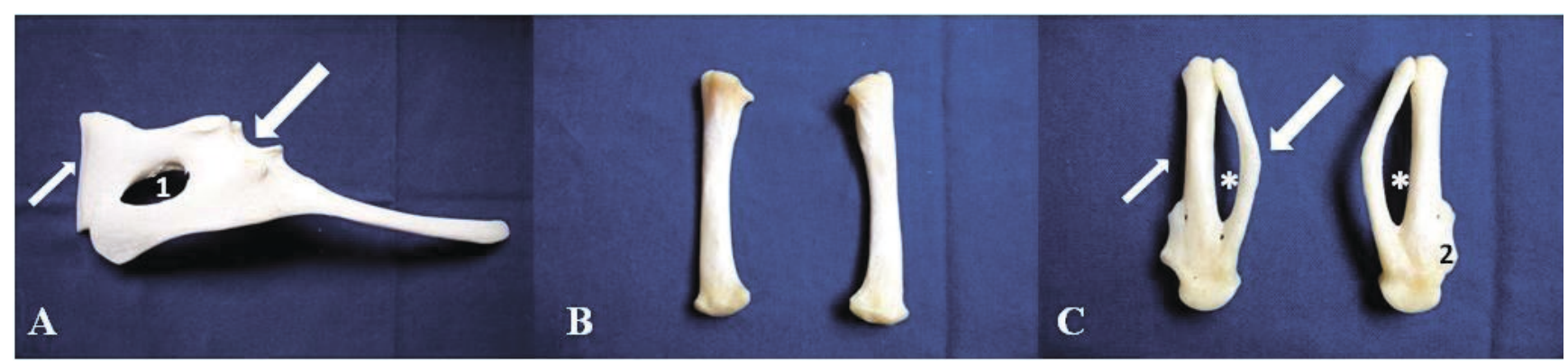


$\mathrm{O}$ rádio mediu $12 \mathrm{~cm}$ de comprimento e $3,3 \mathrm{~cm}$ de circunferência. As epífises do rádio eram pouco destacadas, a epífise proximal apresentou uma cavidade que se articula com o úmero, e a tuberosidade do rádio era pouco evidente. A fóvea se apresentou bem central à cavidade encontrada na epífise proximal. Na epífise distal, foi encontrada uma discreta crista transversa e a formação de uma tuberosidade lateral bem evidente.

A ulna apresentou $13 \mathrm{~cm}$ de comprimento e $4 \mathrm{~cm}$ de circunferência, estava localizada caudalmente ao rádio, e apresentou-se um pouco maior que o mesmo. A diáfise apresentou uma circunferência constante em todo seu comprimento e as epífises eram relativamente destacadas. A ulna não possuiu o olécrano, porém, na epífise proximal ocorreu a formação de uma tuberosidade lateral bem desenvolvida. A extremidade distal da ulna apresentou-se arredondada e lisa, a qual articula com o osso da mão. Na superfície externa do corpo da ulna encontraram-se uma série de pequenas projeções ósseas que representam pontos de inserção para as penas secundárias da asa. Nas aves galiformes estas projeções são reduzidas, nas voadoras fortes elas são muito pronunciadas (GETTY, 1986). As asas das ratitas são relativamente pequenas, sendo utilizadas para manter o equilíbrio durante a corrida, quando se desvia bruscamente ou quando gira (CUBAS et al., 2006).

A mão do avestruz era formada por dois dígitos, o terceiro e o quarto, que estavam unidos pela extremidade proximal, formando uma tuberosidade de face plana e arredondada. $\mathrm{O}$ quarto dígito era formado por um único osso, que se apresentou levemente curvado tendo $7 \mathrm{~cm}$ de comprimento. $\mathrm{O}$ terceiro dígito também era formado por um só osso de $7 \mathrm{~cm}$ de comprimento, apresentando uma circunferência maior que o quarto dígito.

As extremidades distais de ambos os dígitos se articularam com mais um osso, de $3,5 \mathrm{~cm}$ de comprimento. Na mão ainda havia mais um osso de comprimento e diâmetro pequeno, que se articulava em uma borda cranial presente no terceiro dígito. Segundo Getty (1986), no embrião as falanges rudimentares distais podem estar presentes e que subsequentemente fundem-se com o elemento mais proximal. Diferente do avestruz, os pisciformes apresentam quatro dígitos, são zigodáctilos, ou seja, possuem o segundo e terceiro dedos para frente e o primeiro e quarto para trás (CUBAS et al., 2006).

\section{Esqueleto apendicular pélvico}

O membro pélvico de um avestruz é constituído por quatro ossos mais dois dedos e seus respectivos ossos. O primeiro osso é o fêmur (Figura 3A), que é o mais proximal dos ossos da perna. $\mathrm{O}$ fêmur do avestruz avaliado possuiu $32 \mathrm{~cm}$ de comprimento e $14 \mathrm{~cm}$ de circunferência na região da diáfise. $\mathrm{Na}$ extremidade proximal encontrou-se a cabeça do fêmur, que se articulava com o acetábulo. Na cabeça observou-se a fóvea, que é bem evidente, apresentando certa profundidade. Lateralmente à cabeça do fêmur estava o trocanter maior, que era bem evidente e arredondado. Mais caudalmente, encontrou-se o trocanter menor, e não apresentou terceiro trocanter. A face medial e proximal do fêmur apresentou-se relativamente plana, formando uma borda cranial ao trocanter maior. Na epífise distal, foram encontrados os côndilos que se articulam com o tibiotarso e com a fíbula, a fossa para o músculo poplíteo era bem evidente e dividia o côndilo lateral em duas partes, sendo a parte maior a mais medial. Lateralmente em ambos os côndilos foram encontrados os epicôndilos, sendo o epicôndilo medial mais destacado que o lateral. A fossa supracondilar apresentou-se relativamente profunda e encontrava-se proximal ao côndilo medial, mais distal encontrou-se a fossa intercondilar. A tróclea, local onde ocorre a articulação com a patela, era semelhante à de um equino. Segundo Dyce et al. (2004), em sua forma geral, o fêmur do avestruz assemelha-se ao dos mamíferos, sua extremidade proximal palpável pode ser usada para obtenção de amostras de medula óssea.

Em seguida, o tibiotarso (Figura 3B) possuiu $55 \mathrm{~cm}$ de comprimento e $11 \mathrm{~cm}$ de circunferência na região da diáfise e apresentou o côndilo medial mais desenvolvido que o lateral. A eminência intercondilar era pouco evidente, assim como o sulco da tuberosidade do tibiotarso. A borda cranial era bem destacada e restrita à epífise proximal, tendo sua extremidade proximal dividida em duas partes. O tibiotarso do avestruz não apresentou as linhas para o músculo poplíteo, como nos mamíferos. A epífise distal apresentou-se mais discreta que a proximal, tendo $26,5 \mathrm{~cm}$ de circunferência, 
FIGURA 3: Imagens fotográficas dos ossos do esqueleto apendicular pélvico de avestruz macho, adulto. A) fêmur apresentando a cabeça do fêmur (1), a fóvea (seta menor) e a tróclea (seta maior). B) tibiotarso (2) e fíbula (*). C) falange média distal (3) do terceiro dígito e falange distal (seta). D) falanges pertencentes ao quarto dígito.

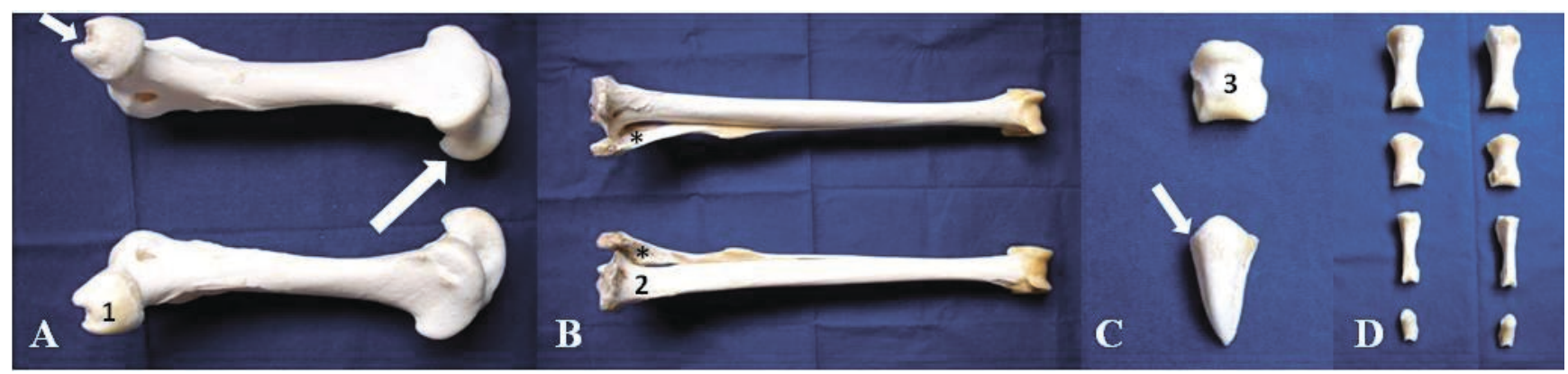

enquanto a proximal apresentou $36 \mathrm{~cm}$ de circunferência. Segundo Dyce et al. (2004), o tibiotarso é formado pela fusão da tíbia com a fileira proximal dos ossos do tarso e é o maior osso do membro pélvico apresentando em sua face lateral a fíbula que é pouco desenvolvida e articula-se proximalmente com o fêmur. O tibiotarso é o correspondente à tíbia dos mamíferos (OLIVEIRA, 2006).

A fíbula (Figura 3B), que estava unida ao tibiotarso, apresentou, no avestruz, $50 \mathrm{~cm}$ de comprimento e acompanhou o tibiotarso em todo seu comprimento, finalizando-se no inicio da epífise distal. Possuiu uma cabeça bem evidente, medindo $12 \mathrm{~cm}$ de circunferência. Apresentou também uma protuberância bem evidente, com distância de $10,5 \mathrm{~cm}$ da cabeça. Após essa protuberância, o diâmetro do corpo da fíbula se manteve constante por $11 \mathrm{~cm}$ e nesse comprimento está bem evidente o espaço interósseo. Em seguida ela se apresentou plana até o seu final. Na galinha, a fíbula apresenta uma condição típica da ave, possui uma fíbula reduzida, entretanto, em determinadas linhagens, por exemplo, Creeper, a fíbula é de tamanho e extensão maiores (GETTY, 1986).

Na sequência, o tarsometatarso do avestruz, possuiu $46 \mathrm{~cm}$ de comprimento e $10,5 \mathrm{~cm}$ de circunferência. A epífise proximal do tarsometatarso apresentou uma borda cranial, de extremidade proximal não muito evidente, que segue até a diáfise com um contorno suave. Os ossos metatársicos II, III e IV são fusionados assim como os ossos do tarso para formar um único osso tarsometatarso ou osso da canela (OLIVEIRA, 2006). De acordo com Getty (1986), no tarsometatarso do galo há um centro ósseo da espora, que surge do lado interno do osso, aproximadamente dois terços distalmente ao longo do osso, diferentemente da avestruz. A epífise distal do tarsometatarso do avestruz era dividida por um sulco profundo, separando-a em duas estruturas de circunferências distintas, sendo a medial maior. Fowler (1991) cita a ausência da patela nas ratitas, entretanto, no avestruz e na ema, um dos ossos tarsais da articulação tibiotarsometatarsica permanece solto, e assemelha funcionalmente à patela.

$\mathrm{O}$ avestruz apresentou dois dígitos, o terceiro e o quarto (Figuras $3 \mathrm{C}$ e D). O terceiro dígito (Figura 3C) é formado por três falanges, além de uma falange que se assemelha à forma da unha, a falange distal. Os comprimentos foram de $8,5 \mathrm{~cm}$ da falange proximal, $5,5 \mathrm{~cm}$ da média proximal, $3 \mathrm{~cm}$ da média distal, e $6,5 \mathrm{~cm}$ da falange distal. O quarto dígito era formado por quatro falanges. As quatro falanges juntas apresentaram $12,5 \mathrm{~cm}$ de comprimento, sendo referidas as falanges de proximal a distal e apresentaram $7,5 \mathrm{~cm}, 2,5 \mathrm{~cm}, 1,5 \mathrm{~cm}$ e $1 \mathrm{~cm}$ de comprimento. Segundo Cubas et al. (2006), a ema possui três dedos, como todas as ratitas, com exceção dos avestruzes que só possuem dois, caso único nas aves, tendo regredido ao longo de sua evolução a dois dedos.

O conhecimento acerca do sistema ósseo do avestruz (Struthio camelus) é indispensável no entendimento das doenças que acometem a formação óssea e o desenvolvimento do aparelho locomotor do animal. Segundo Garcia (2012), dentre os principais problemas a rotação tíbio-társica, a síndrome do entortamento das pernas, o desvio de pernas e o entortamento de dedos são os mais frequentes. De acordo com Oliveira et al. 
(2010), podem ser encontrados também a subluxação de articulação metatarsofalangeana e as alterações de falanges, que são menos frequentes. A necessidade de estudos e pesquisas realizadas nessa área morfologia é inquestionável, sendo de grande importância hoje na criação comercial do animal. Logo, estudos acerca do sistema musculoesquelético do avestruz vêm obtendo destaque e importância científica.

\section{Referências}

ARTONI, S. M. B.; COSTA, F. N.; PACHECO, M. R.; STEFANINI, M. A.; ORSI, A. M.; ARAÚJO, M. L. Descrição anatômica do esqueleto do cisne (Cygnus melanochoriphus). Biotemas, Florianópolis, v. 14, n. 2, p. 99-108. 2001.

BAUMEL, J. J. Handbook of avian anatomy: nomina anatômica avium. 2 ed. Cambridge: Nuttall Ornithological Club, 1993. 779 p.

CEPLAC. Criação de avestruz. 2008. Disponível em <http:// www.ceplac.gov.br/radar/semfaz/avestruz.htm>. Acesso em: 09 jun. 2011.

CUBAS, Z. S.; SILVA, J. C. R.; CATÃO-DIAS, J. L. Tratado de animais selvagens. São Paulo: Roca, 2006. 1376 p.

DYCE, K. M.; SACK, M. O.; WENSING, C. J. G. Anatomia das aves. In: DYCE, K. M.; SACK, M. O.; WENSING, C. J. G. (Ed.). Tratado de anatomia veterinária. 3 ed. Rio de Janeiro: Elsevier, 2004. p. 775-780.
FOWLER, E. M. Comparative clinical anatomy of ratites. Journal of Zoo and Wildlife Medicine, Yulee, v. 22, n. 2, p. 204-227, 1991.

GARCIA, R. G. Problemas de pernas em avestruzes - Revisão. 2012. Disponível em: <http://br.monografias.com/trabalhos/ problemas-pernas-avestruzes/problemas-pernas-avestruzes shtml>. Acesso em: 14 jan. 2012.

GETTY, R. Sisson/Grossman: anatomia dos animais domésticos. 5 ed. Rio de Janeiro: Guanabara Koogan, 1986. 2000 p.

JULIAN, R. J.; RIDDELL, C. Desordenes no infecciosos del esqueleto de las aves domesticas y de los pavos. 1996. American Association of Avian Pathologists, INC. Disponível em: <http:// talentosenahoy.blogspot.com/2009/05/atlas-de-patologia-aviar. html>. Acesso em: 10 jan. 2012.

NOGUEIRA JÚNIOR, S. Avestruz, um bom negócio. 2005. Disponível em: <http://www. Iea.gov.br/out/vertexto php?codtexto $=3799>$. Acesso em: 15 mar. 2008 .

OLIVEIRA, P. P. Acupuntura em aves. 2006. 29 f. Monografia (Especialização em Acupuntura Veterinária) - Universidade Estadual Paulista "Júlio de Mesquita Filho", Botucatu. 2006.

OLIVEIRA, R. P. Estudo do membro pélvico do avestruz: considerações anatômicas, radiográficas e histológicas da rotação tibiotársica. 2005. 98 f. Dissertação (Mestrado em Anatomia dos Animais Domésticos e Silvestres) - Universidade de São Paulo, Brasil. 2005.

OLIVEIRA, R. P.; SAVIANI, G.; CARVALHO, H. S.; MARQUES, V. B.; ALBUQUERQUE, R. A. Estudo do membro pélvico do avestruz: considerações anatômicas, radiográficas e histológicas da rotação tibiotársica. Brazilian Journal of Veterinary Research and Animal Science, São Paulo, v. 47, n. 3, p. 197 203, 2010 